06,13

\title{
Электропроводность и барьерные свойства тонких пленок ниобата лития*
}

\author{
() С.И. Гудков ${ }^{1}$, К.Д. Бакланова ${ }^{1}$, М.В. Каменщиков ${ }^{1}$, А.В. Солнышкин ${ }^{1,2}$, А.Н. Белов ${ }^{2}$ \\ ${ }^{1}$ Тверской государственный университет, \\ Тверь, Россия \\ ${ }^{2}$ Национальный исследовательский университет „Московский институт электронной техники“, \\ Москва, Зеленоград, Россия \\ E-mail: sergej-gudkov-i@yandex.ru
}

Методами вольт-фарадных и вольт-амперных характеристик исследованы тонкопленочные структуры на основе $\mathrm{LiNbO}_{3}$, сформированные различными способами: методом лазерной абляции и методом магнетронного распыления. По вольт-фарадным характеристикам определена величина потенциального барьера на интерфейсе $\mathrm{Si}-\mathrm{LiNbO}_{3}$ для обоих типов пленок. Анализ вольт-амперных характеристик выявил наличие в исследуемых структурах нескольких механизмов проводимости. В пленке $\mathrm{LiNbO}_{3}$, изготовленной методом лазерной абляции, основной вклад в электропроводность дают эффект Пула-Френкеля и токи, ограниченные пространственным зарядом. В пленочной гетероструктуре, изготовленной методом магнетронного распыления, основной механизм - токи, ограниченные пространственным зарядом.

Работа выполнена при финансовой поддержке Российского научного фонда (грант № 15-19-00138).

DOI: 10.21883/FTT.2018.04.45685.09D

Одним из важнейших сегнетоэлектрических соединений, применяемых в оптоэлектронике, является ниобат лития $\left(\mathrm{LiNbO}_{3}\right)[1,2]$. В настоящее время частым явлением стало использование этого материала в виде пленок, свойства которых зачастую зависят от способа их синтеза, типа подложки, материалов электродов, а также структурных несовершенств и примесей, что делает актуальным исследование этих структур [3].

Ниобат лития обладает отличными электрооптическими, нелинейными и акустооптическими свойствами, что позволяет его использовать в фотонике [4]. $\mathrm{LiNbO}_{3}$ может легко легироваться редкоземельными ионами с целью получения материала для применения в лазерной технике. Периодически поляризованный $\mathrm{LiNbO}_{3}$ используется для изготовления оптических параметрических генераторов для создания перестраиваемых лазеров в видимом и среднем инфракрасном излучении, тандемно-полюсные кристаллы ниобата лития - для широкополосного источника зеленого света, лазерных проекторов или дисплейных устройств, а также как материал фотонного запрещенного зазора. Кроме того, существует значительный интерес к микроструктурированию кристаллов ниобата лития для их использования в микроэлектромеханической системе (MEMS) [5,6].

Цель данной работы заключается в исследовании барьерных эффектов и механизмов проводимости структур с тонким сегнетоэлектрическим слоем $\mathrm{LiNbO}_{3}$, нанесенным различными методами, поскольку данные свойства влияют на работу функциональных элементов на основе пленок ниобата лития.

\footnotetext{
* Доклад на XIV Международной конференции „Физика диэлектриков“" (Санкт-Петербург. 29 мая-2 июнгя 2017 г.)

Материалы конференции частично опубликованы в выпуске № 3 за 2018 г. журнала „Физика твердого тела“.
}

Исследования проводились на тонкопленочных структурах $\mathrm{Cu} / \mathrm{LiNbO}_{3} / \mathrm{Si}$, изготовленных в НИТУ „МИСиС“. Нанесение ниобата лития на кремниевую подложку толщиной $0.54 \pm 0.01 \mathrm{~mm}$ осуществлялось методом лазерной абляции (образец № 1). Толщина слоя $\mathrm{LiNbO}_{3}$ составляла $100 \mathrm{~nm}$. Стоит отметить, что поверхность образца не является гладкой. На свободную поверхность пленки методом магнетронного распыления были нанесены медные электроды диаметром $2.45 \pm 0.05 \mathrm{~mm}$. Образец № 2 получен методом магнетронного распыления [7]. Для данного образца толщина кремниевой подложки составляет $0.53 \pm 0.01 \mathrm{~mm}$. Толщина слоя $\mathrm{LiNbO}_{3}$ в этом случае $-200 \mathrm{~nm}$. Для данного образца диаметр медных электродов, нанесенных на свободную поверхность пленки, составил $2.4 \pm 0.2 \mathrm{~mm}$.

Фазовый состав данных образцов, полученных методом магнетронного распыления, исследовался ранее [7]. $\mathrm{B}$ данной работе показано, что наряду с фазой $\mathrm{LiNbO}_{3}$ в исследованных образцах существует и фаза $\mathrm{LiNb}_{3} \mathrm{O}_{8}$. Соотношение фаз в пленках можно изменить путем постростового отжига. В исследуемых нами пленках фаза $\mathrm{LiNb}_{3} \mathrm{O}_{8}$ практически отсутствует. Для образца, полученного методом лазерной абляции, наблюдается аналогичная картина.

На данный момент считается [8], что имеется две компоненты, вносящие вклад в проводимость ниобата лития: ионная, связанная с ионами $\mathrm{H}^{+}$, неконтролируемо входящими в состав ниобата лития в процессе роста кристалла, и электронная, имеющая место при более низких температурах. Используемые для нанесения пленок ниобата лития кремниевые подложки имели $p$-тип проводимости.

Для определения барьерных свойств исследуемых структур были получены вольт-фарадные характеристики (ВФХ) с помощью измерителя иммитанса Е7-20 

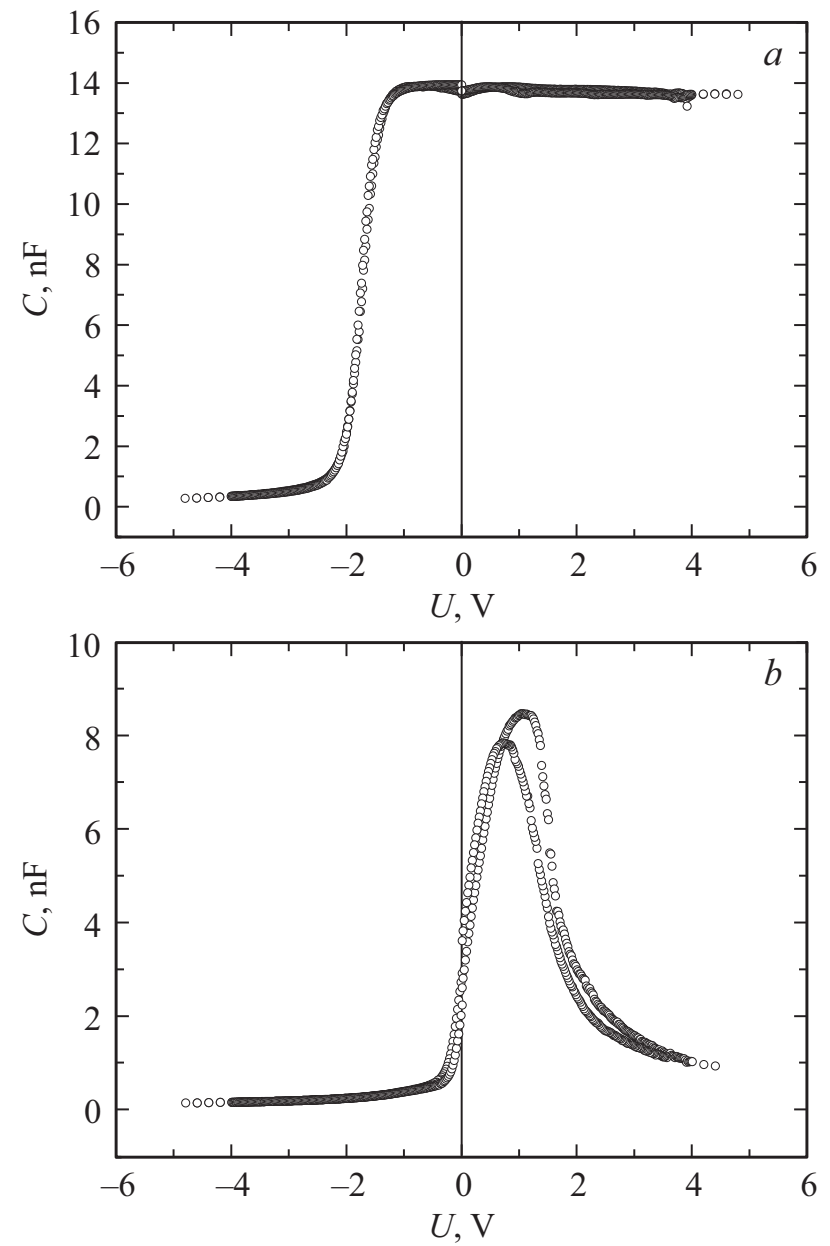

Рис. 1. Вольт-фарадные характеристики для образцов $\mathrm{Cu} / \mathrm{LiNbO}_{3} / \mathrm{Si}: a-$ образец № $1, b-$ образец № 2 .

в синусоидальных полях амплитудой $0.04 \mathrm{~V}$ и частотой $1 \mathrm{kHz}$. Задержка перед измерением значения емкости при определенной величине напряжения смещения составляла $1 \mathrm{~s}$. Вольт-амперные характеристики (BAX) получены при приложении постоянного напряжения в интервале от -5 до $5 \mathrm{~V}$. Напряжение считается положительным при приложении положительного потенциала к верхнему электроду пленочного образца и отрицательным при обратном приложении потенциалов.

На рис. 1 показаны ВФХ, полученные в результате исследования диэлектрических свойств. Из графика, представленного на рис. $1, a$, видно, что для образца № 1 в интервалах от -5 до $-2.5 \mathrm{~V}$ и от -1 до $5 \mathrm{~V}$ емкость меняется в незначительных пределах (от 0.3 до $0.8 \mathrm{nF}$ и от 13.9 до $13.6 \mathrm{nF}$ соответственно). В интервале от -2.5 до $-1 \mathrm{~V}$ емкость претерпевает значительное изменение, достигая максимального значения в районе $-1 \mathrm{~V}$. Для ВФХ образца № 2, показанных на рис. $1, b$, при приложении положительного напряжения наблюдается максимум, а также несовпадение прямого и обратного ходов. Одной из возможных причин наличия максимума является переполяризация сегнетоэлектрического слоя.
Для первого образца вклад процессов переключения поляризации в диэлектрический отклик может быть завуалирован некоторыми эффектами, в частности более сильным изменением емкости барьерного слоя, по сравнению со вторым образцом. Также процессы переключения достаточно сложно наблюдать в образцах с высокой удельной проводимостью, механизмы образования которой в пленках ниобата лития обсуждаются далее.

На основе вольт-фарадных характеристик определена величина потенциального барьера на интерфейсе $\mathrm{Si}-\mathrm{LiNbO}_{3}$ согласно [9]. Данная модель была использована для случая сегнетоэлектрика в работах $[10,11]$. Известно, что дифференциальная емкость $C=d Q / d U$ для гетероструктуры при отрицательном смещении $\left(U_{\mathrm{rev}}\right)$ может быть представлена в следующем виде:

$$
C^{-2}=\left(2 / S^{2} q N_{d} \varepsilon_{n}\right)\left(\varphi_{b}-\xi+U_{\mathrm{rev}}-k T / q\right),
$$

где $S$ - площадь контакта, $q-$ эффективный заряд носителей, $N_{d}-$ концентрация донорных уровней, $\varepsilon_{n}$ - диэлектрическая проницаемость полупроводника, $\varphi_{b}-$ величина потенциального барьера, $\xi=(k T / q) \ln \left(N_{c} / N_{d}\right)$ - расстояние от уровня Ферми
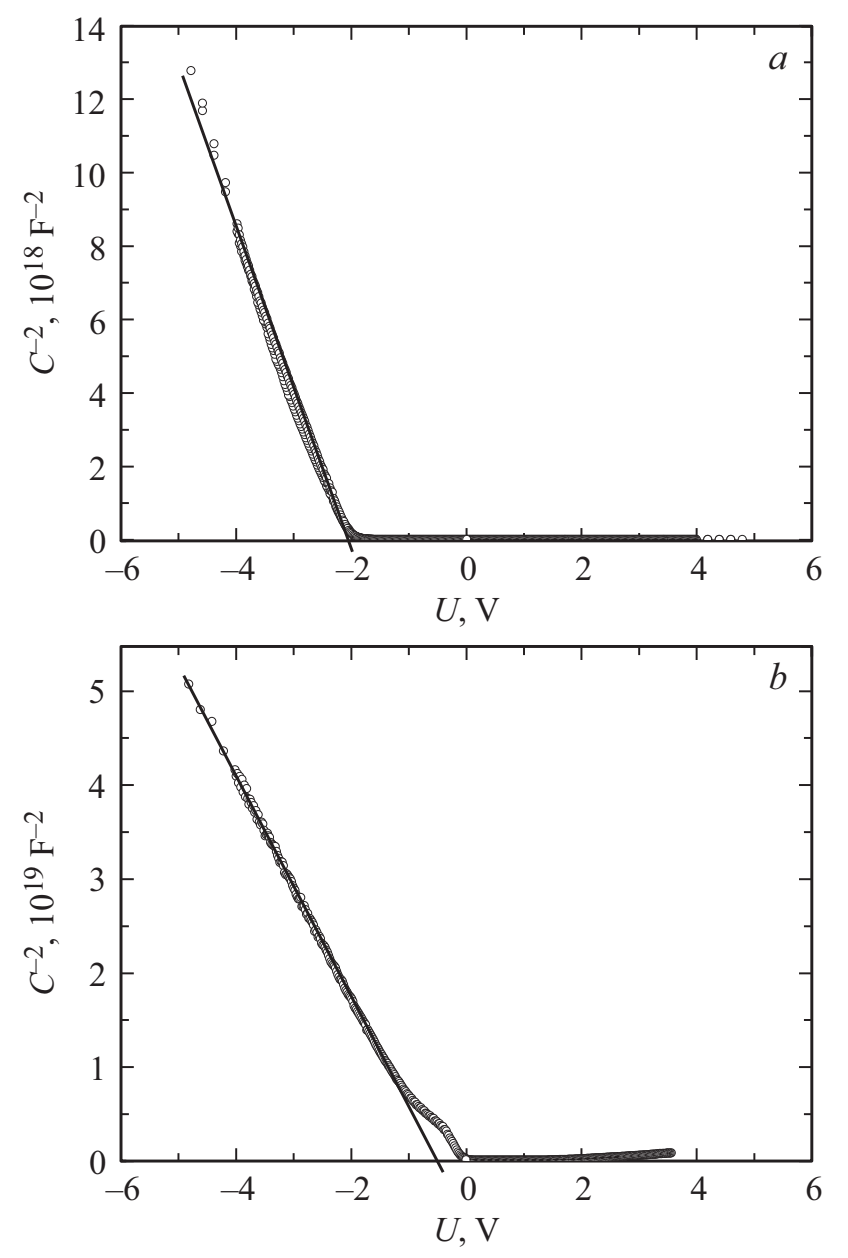

Рис. 2. Зависимости $C^{-2}$ от $U$ для тонкопленочных структур $\mathrm{Cu} / \mathrm{LiNbO}_{3} / \mathrm{Si}: a-$ образец № $1, b$ - образец № 2 . 
до дна валентной зоны, $N_{c}$ - эффективная плотность состояний, $k$ - постоянная Больцмана, $T-$ абсолютная температура.

В этом рассмотрении считаем, что проводимость кремниевой подложки близка к металлической, поэтому с определенной степенью точности применение соотношения (1) допустимо для нашего случая. Таким образом, экстраполяция кривой $C^{-2}(U)$ к оси абсцисс дает значение встроенного потенциала $V_{b}$, из которого можно определить величину потенциального барьера согласно формуле

$$
\varphi_{b}=V_{b}+\xi+k T / q,
$$

где $V_{b}-$ напряжение отсечки. Величина $\xi+k T / q$ крайне мала, что делает возможным при вычислении $\varphi_{b}$ ограничиться только величиной напряжения отсечки $V_{b}$. На рис. 2 представлены графики зависимости $C^{-2}(U)$ для исследуемых образцов с экстраполяцией по отрицательным напряжениям.

При анализе полученных зависимостей $C^{-2}(U)$ было установлено, что высота потенциального барьера для интерфейса $\mathrm{Si}-\mathrm{LiNbO}_{3}$ для образца № 1 составляет около $2 \mathrm{eV}$, а для образца № 2 - около $0.5 \mathrm{eV}$.

Методом вольт-амперных характеристик проведены исследования электропроводности обоих образцов тонких пленок ниобата лития. Результаты измерений приведены на рис. 3. Как следует из представленных зависимостей тока от приложенного напряжения, в пленках проявляются различные механизмы проводимости, соответствующие определенным интервалам электрических полей.

Известно [12], что в пленочных структурах возможен вклад в электропроводность следующих механизмов проводимости: эффект Пула-Френкеля, эффект Шоттки, токи, ограниченные пространственным зарядом, туннелирование Фаулера-Нордгейма и др.

Эффект Пула-Френкеля, согласно [13], заключается в изменении величины потенциальных барьеров, преодолеваемых носителями заряда, между атомами кристаллической решетки при приложении поля. Этот эффект описывается следующей зависимостью:

$$
J \propto E \exp \left(\frac{q}{k T}\left[2 \sqrt{\frac{q E}{4 \pi \varepsilon_{0} \varepsilon_{\infty}}}-\varphi_{t}\right]\right),
$$

где $J-$ плотность тока, $E-$ напряженность приложенного поля, $\varepsilon_{0}-$ электрическая постоянная, $\varepsilon_{\infty}-$ высокочастотная диэлектрическая проницаемость, $\varphi_{t}$ величина потенциального барьера.

Эффект Шоттки связан с уменьшением высоты потенциального барьера на интерфейсе при приложении поля. Данный эффект описывается следующим соотношением:

$$
J=A^{*} T^{2} \exp \left(\frac{q}{k T}\left[\sqrt{\frac{q E}{4 \pi \varepsilon_{0} \varepsilon_{\infty}}}-\varphi_{b}\right]\right),
$$

где $A^{*}$ - постоянная Ричардсона.
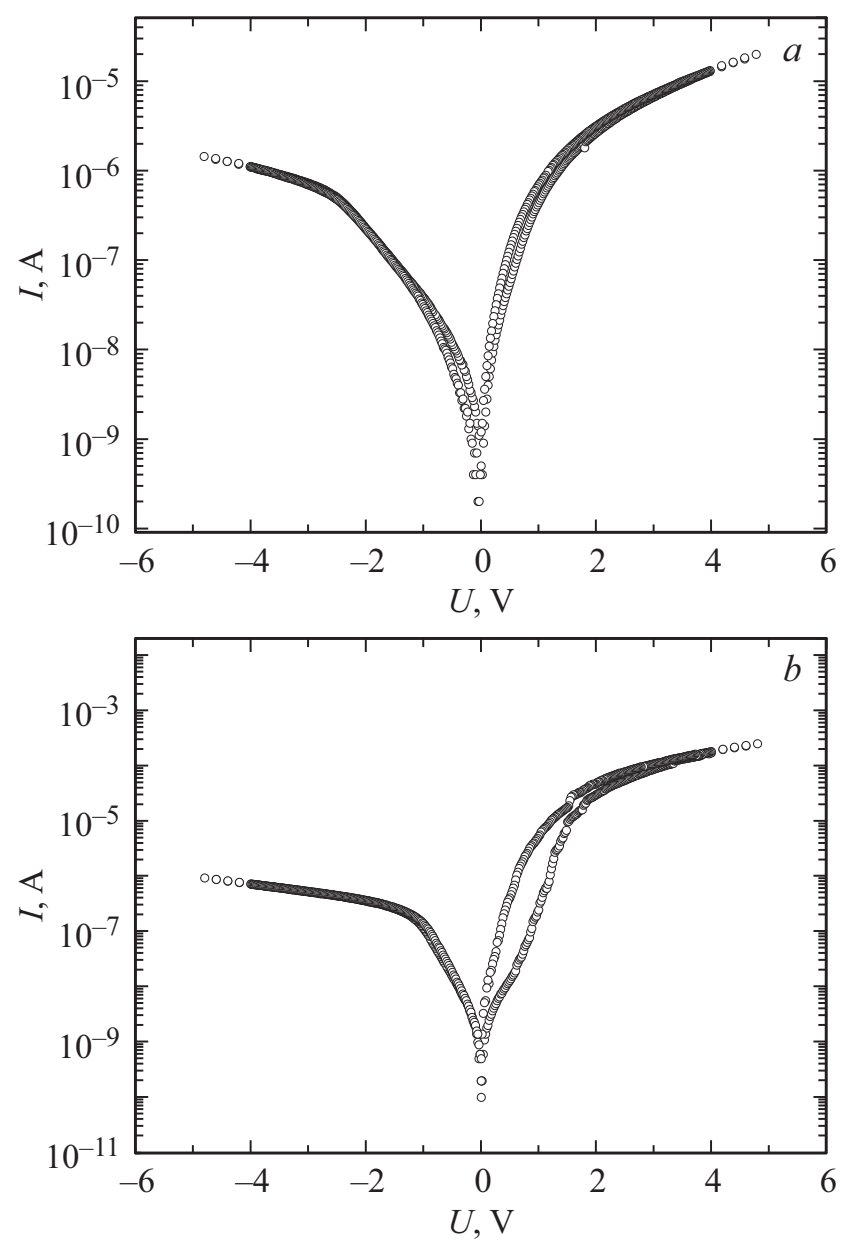

Рис. 3. Вольт-амперные характеристики для тонкопленочных структур $\mathrm{Cu} / \mathrm{LiNbO}_{3} / \mathrm{Si}$, представленные в полулогарифмическом масштабе: $a$ - образец № $1, b$ - образец № 2 .

Токи, зависящие от находящегося в объеме полупроводника заряда, называются токами, ограниченными пространственным зарядом (ТОПЗ). Согласно [14], такие токи описываются квадратичным законом Мотта:

$$
J=\frac{9}{8} \tau_{\mu} \sigma_{0} \mu \frac{U^{2}}{L^{3}},
$$

где $\tau_{\mu}-$ максвелловское время релаксации, $\sigma_{0}-$ удельная электропроводность в объеме материала в отсутствие инжекции, $\mu-$ подвижность носителей заряда, $U$ - приложенное напряжение, $L-$ толщина образца.

На основе вольт-амперной характеристики для образца № 1 сделано предположение о превалирующих механизмах проводимости для каждого интервала полей, соответствующих определенным участкам ВАХ. На участке от -5 до $-3 \mathrm{~V}$ преобладают токи, ограниченные пространственным зарядом, интервал от -3 до $-1 \mathrm{~V}$ графически удовлетворяет механизмам Пула-Френкеля и Шоттки. В связи с этим был произведен расчет величины оптической (высокочастотной) диэлектрической проницаемости, из которой можно получить показатель 
преломления $n=\sqrt{\varepsilon_{\infty}}$. Расчеты дали следующие значения: для эффекта Пула-Френкеля $n=2.9$, для эффекта Шоттки $n=1.36$. К табличному значению показателя преломления ниобата лития $(n=2.29)$ ближе значение, полученное при расчете для эффекта Пула-Френкеля. Таким образом, на участке напряжений от -3 до $-1 \mathrm{~V}$ доминирующим является эффект Пула-Френкеля. При напряжениях от -1 до $1 \mathrm{~V}$ доминирующий механизм проводимости не выявлен. В интервале от 1 до $5 \mathrm{~V}$ основным механизмом проводимости является ТОПЗ.

Для образца № 2 на участке от -0.5 до $0.5 \mathrm{~V}$ доминирующим является омический механизм проводимости. В интервалах приложенного напряжения от -5 до $-2 \mathrm{~V}$ и от 0.5 до $5 \mathrm{~V}$ преобладающим механизмом проводимости являются токи, ограниченные пространственным зарядом. Область приложенных напряжений от -2 до $-0.5 \mathrm{~V}$ определена как переходная, где преобладающий механизм проводимости на данный момент не установлен.

Были исследованы и проанализированы вольт-фарадные и вольт-амперные характеристики тонкопленочных структур ниобата лития, изготовленных различными методами. В ходе исследования установлена величина потенциального барьера, возникающего на интерфейсе $\mathrm{Si}-\mathrm{LiNbO}_{3}$. Для образца, изготовленного методом лазерной абляции, она составила около $2 \mathrm{eV}$, а для образца, изготовленного методом магнетронного распыления, около $0.5 \mathrm{eV}$. По вольт-амперным характеристикам установлены доминирующие при различных значениях напряжения механизмы проводимости. Для образца, изготовленного методом лазерной абляции, доминирующими являются эффект Пула-Френкеля и токи, ограниченные пространственным зарядом, а для тонкопленочной структуры, произведенной методом магнетронного распыления, - токи, ограниченные пространственным зарядом.

Авторы выражают глубокую благодарность Д.А. Киселеву (НИТУ „МИСиС“) за любезно предоставленные для исследований образцы пленок ниобата лития.

\section{Список литературы}

[1] Ю.С. Кузьминов. Электрооптический и нелинейно-оптический кристалл ниобата лития. Наука, М. (1987). 264 с.

[2] Н.В. Сидоров, Т.Р. Волк, Б.Н. Маврин, В.Т. Калинников. Ниобат лития: дефекты, фоторефракция, колебательный спектр, поляритоны. Наука, М. (2003). 255 с.

[3] Piezoelectric MEMS Resonators / ed. by Harmeet Bhugra and Gianluca Piazza. Springer International Publishing, Switzerland. (2017). 424 p.

[4] L. Cai, Y. Wang, H. Hu. Optics Lett. 40, 3013 (2015).

[5] L. Cai, S. Li, H. Han, H. Hu. Optics Express 23, 1240 (2015).

[6] R. Bhatt, I. Bhaumik, S. Ganesamoorthy, R. Bright, M. Soharab, A. Kumar Karnal, P. Kumar Gupta. Crystals 7, 23 (2017).
[7] Д.А. Киселев, Р.Н. Жуков, А.С. Быков, М.И. Воронова, К.Д. Щербачев, М.Д. Малинкович, Ю.Н. Пархоменко. Неорган. материалы 50, 453 (2014).

[8] С.В. Евдокимов, А.В. Яценко. ФТТ 48, 317 (2006).

[9] Э.Х. Родерик. Контакты маталл-полупроводник. Радио и связь, М. (1982). 208 с.

[10] B.H. Park, S.J. Hyun, C.R. Moon, Byung-Doo Choe, J. Lee, C.Y. Kim, W. Jo, T.W. Noh. J. Appl. Phys. 84, 4428 (1998).

[11] M. Maleto, E. Pevtsov, A. Sigov, A. Svotina. Integrated Ferroelectrics: J. 43, 65 (2002).

[12] К.Л. Чопра. Электрические явления в тонких пленках / Пер. с англ. А.Ф. Волкова, Е.И. Гиваргизова, П.И. Перова, В.И. Покалякина, под ред. проф. Т.Д. Шермергора. Мир, М. (1972). $424 \mathrm{c}$.

[13] В.И. Фистуль. Введение в физику полупроводников. Высш. школа, М. (1984). 352 c.

[14] В.Л. Бонч-Бруевич, С.Г. Калашников. Физика полупроводников. Наука, М. (1990). 672 с. 